\title{
USABILITY TESTING PADA SIMULATOR MEDIA PEMBELAJARAN LALU LINTAS BERBASIS ANDROID
}

\author{
I Made Ari Saputra*1, I Putu Agung Bayupati², Ni Kadek Dwi Rusjayanthi \\ 1,2,3 Teknologi Informasi, Universitas Udayana \\ Email: ${ }^{1}$ imadearisaputra@gmail.com, ${ }^{2}$ bayuhelix@yahoo.com, ${ }^{3}$ dwi.rusjayanthi@unud.ac.id \\ *Penulis Korespondensi
}

(Naskah masuk: 25 oktober 2020, diterima untuk diterbitkan: 18 Maret 2021)

\begin{abstract}
Abstrak
Kurangnya kesadaran masyarakat terhadap aturan lalu lintas merupakan penyebab sering terjadinya kecelakaan di Indonesia. Masyarakat kesulitan untuk mempelajari aturan lalu lintas pada dunia nyata secara langsung karena resiko kecelakaan. Masyarakat Indonesia perlu mendapat edukasi lebih terhadap aturan lalu lintas yang ada. Simulator lalu lintas merupakan media pembelajaran yang ditunjukan kepada masyarakat agar masyarakat dapat mempelajari aturan lalu lintas secara virtual. Simulator lalu lintas dapat digunakan oleh masyarakat untuk melakukan eksplorasi tentang fungsi rambu lalu lintas dan marka jalan yang ada pada dunia nyata tanpa adanya risiko. Simulator lalu lintas menggunakan metode usability testing untuk mengukur dampak penggunaan simulator lalu lintas terhadap pengetahuan user. Metodologi penelitian simulator lalu lintas menggunakan metode waterfall. Pengujian usability testing pada simulator lalu lintas menunjukan hasil yang baik. Simulator edukasi lalu lintas dapat meningkatkan pengetahuan user tentang rambu lalu lintas dan marka jalan. Simulator lalu lintas dapat memberikan gambaran tentang aturan lalu lintas kepada masyarakat yang akan mengikuti ujian SIM (Surat Ijin Mengemudi).
\end{abstract}

Kata kunci: simulator lalu lintas, usability testing, media pembelajaran lalu lintas.

\section{USABILITY TESTING ON ANDROID-BASED TRAFFIC EDUCATIONAL MEDIA}

\begin{abstract}
The lack of public awareness about traffic regulation is a cause of frequent traffic accidents in Indonesia. People find it difficult to learn traffic rules in the real world directly because of the risk of accidents. Indonesian people need to get more education about the existing traffic rules. The traffic simulator is a learning media that is shown to the public so that people can learn about traffic rules virtually. Furthermore, the traffic simulators can be used by the people to explore the functions of traffic signs and road markings in the real world without any risk. The traffic simulator uses the usability testing method to measure the impact of using the traffic simulator on user knowledge. The research method of traffic simulator is waterfall method. Usability testing on the traffic simulator shows good results. Traffic education simulators can increase user knowledge about traffic signs and road marking. Traffic simulators can provide an overview of traffic rules to people who will take the SIM (Driving License) exam.
\end{abstract}

Keywords: traffic simulator, usability testing, traffic learning media.

\section{PENDAHULUAN}

Pelanggaran terhadap lalu lintas di Indonesia masih sering dilakukan baik disengaja maupun tidak disengaja sehingga menyebabkan kemacetan hingga kecelakaan. Penyebab banyaknya pelanggaran terhadap lalu lintas di Indonesia salah satunya karena kurangnya kesadaran masyarakat agar tertib terhadap rambu lalu lintas dan marka jalan yang ada. Masyarakat Indonesia perlu mendapatkan edukasi lebih tentang rambu lalu lintas dan marka jalan yang ada (UTAMA \& MARIADI, 2019). Salah satu cara yang bisa membantu untuk mengedukasi masyarakat tentang rambu lalu lintas dan marka jalan adalah membuat media pembelajaran mengenai lalu lintas.

Simulator merupakan sebuah alat yang bisa dijadikan media pembelajaran untuk membantu mengedukasi masyarakat mengenai rambu lalu lintas dan marka jalan yang ada di Indonesia. Simulator memiliki gambar 3 dimensi sehingga memberikan kesan nyata kepada user yang memainkannya. Simulator yang dibuat pada 
penelitian ini khusus untuk pengendara mobil. User dirancang dapat mengendarai mobil pada simulator dan harus mengikuti aturan rambu lalu lintas dan marka jalan sesuai dengan yang ada di Indonesia.

Penelitian tentang rambu lalu lintas pernah dilakukan oleh jaya dkk pada tahun 2015. Penelitian berjudul Game Edukasi Rambu Lalu Lintas Berbasis Android. Game tersebut merupakan sebuah game lalu lintas ber-genre multiple choice. Metode yang digunakan pada game tersebut adalah metode pengacakan Fisher-Yates. Game edukasi rambu lalu lintas bertujuan untuk dapat membantu para pengendara kendaraan bermotor dalam mengenali, mempelajari dan menghafal arti dari rambu lalu lintas (JAYA, BUANA, \& WIRANATHA, 2015).

Penelitian yang berjudul Game Edukasi Rambu Lalu Lintas Berbasis Android dengan Metode Fisher-Yates yang dilakukan oleh rajagukguk dan purba pada tahun 2018 membahas tentang cara untuk meminimalisir pelanggaran terhadap rambu lalu lintas dan meningkatkan pemahaman tentang rambu-rambu lalu lintas melalui pengenalan atau sosialisasi rambu-rambu dan aturan lalu lintas dalam bentuk game edukasi. Game yang dibuat adalah game multiple choice menggunakan metode Fisher-Yates (RAJAGUKGUK \& PURBA, 2018).

Simulator lalu lintas merupakan media pembelajaran lalu lintas yang menciptakan lingkungan berbasis skenario, dimana masyarakat dapat berinteraksi untuk menerapkan pengetahuan yang dimiliki dan keterampilan praktis untuk menyelesaikan masalah pada dunia nyata. Simulator merupakan sebuah alat yang dinamis, mewakili kenyataan, kebenaran, akurasi, dan validitas. Simulator membantu masyarakat untuk memperoleh pengetahuan yang interaktif, autentik dan mandiri (VLACHOPOULOS \& MAKRI, 2017). Simulator lalu lintas merupakan aplikasi berbentuk 3D yang bisa dimainkan oleh user dimana user harus menyelesaikan tantangan dengan mengikuti aturan lalu lintas yang ada pada simulator yang sudah disesuaikan dengan aturan lalu lintas yang ada di Indonesia. Simulator edukasi lalu lintas merupakan penggambaran dunia nyata dalam bentuk virtual sehingga user dapat melakukan eksplorasi tentang rambu lalu lintas dan marka jalan tanpa adanya resiko karena tidak turun ke jalan secara langsung sehingga bisa menyelesaikan masalah pada dunia nyata. Metodologi penelitian simulator lalu lintas menggunakan metode waterfall. Metodologi penelitian simulator lalu lintas yaitu studi literatur, perancangan, implementasi dan pengujian. Metode collision detection digunakan pada simulator lalu lintas agar simulator dapat mendeteksi terjadinya tabrakan antar objek ketika user memainkannya. Pengujian simulator edukasi lalu lintas menggunakan metode usability testing untuk mengukur kepuasan user terhadap simulator.
Simulator media pembelajaran rambu lalu lintas di Indonesia terdiri dari tiga scene yaitu Free mode scene, direction scene, dan tutorial scene. Simulator media edukasi lalu lintas di Indonesia dibuat untuk perangkat Android karena Android yang bersifat open source dan Android merupakan operating system yang paling banyak digunakan pada saat ini. Alat pengembangan Android disediakan secara gratis sehingga banyak aplikasi yang bisa dihasilkan dengan menggunakan platform Android salah satunya adalah simulator lalu lintas. Android juga menyediakan platform perangkat keras yang sangat nyaman untuk pengembang sehingga pengembang dapat untuk mewujudkan ide yang dimiliki dengan menghabiskan lebih sedikit upaya. Android merupakan perangkat yang semakin populer dimana kegiatan yang biasanya dilakukan di komputer bisa dilakukan pada perangkat Android seperti mendengarkan music, menonton video dan lainnya, sehingga penggunaan platform Android untuk pengembangan simulator edukasi lalu lintas di Indonesia akan lebih efektif dan efisien (PRAYOGA, BUANA, \& WIRANATHA, 2017), (PRAYUDA, BAYUPATI, \& WIRANATHA, 2016), (KUSNIYATI \& SITANGGANG, 2016).

\section{METODE PENELITIAN}

Metodologi yang digunakan pada penelitian ini adalah metode waterfall. Metodologi penelitian simulator lalu lintas dapat dilihat pada gambar 1 .

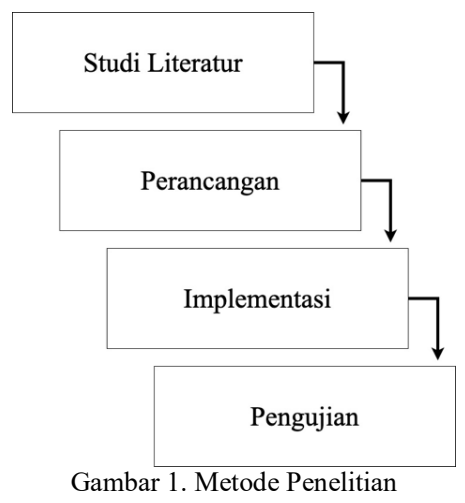

Gambar 1 merupakan metode penelitian dari simulator lalu lintas. Metode yang digunakan pada penelitian ini adalah metode waterfall. Metode waterfall merupakan sistem linier dimana hasil dari tahap sebelumnya akan menjadi masukan untuk tahap berikutnya (TRISTIANTO, 2018). Terdapat empat tahapan pada metodologi penelitian ini yaitu studi literatur, perancangan, implementasi dan pengujian.

\subsection{Studi Literatur}

Penelitian ini menggunakan pendekatan kualitatif dengan metode studi literatur untuk mengumpulkan data dan informasi dari buku-buku, jurnal, e-book, internet dan sumber-sumber lain 
yang saling berkaitan (SYUKWANSYAH, 2016). Studi literatur yang dilakukan untuk mencari informasi meliputi undang-undang tentang penggunaan rambu lalu lintas dan marka jalan di Indonesia, pembuatan simulator dalam bentuk 3D dan pengembangan aplikasi Android, aplikasi tentang lalu lintas di Indonesia.

\subsection{Perancangan}

Tahap perancangan simulator lalu lintas merupakan tahapan yang dilakukan setelah melakukan studi literatur. Perancangan simulator lalu lintas menggunakan metode UML.

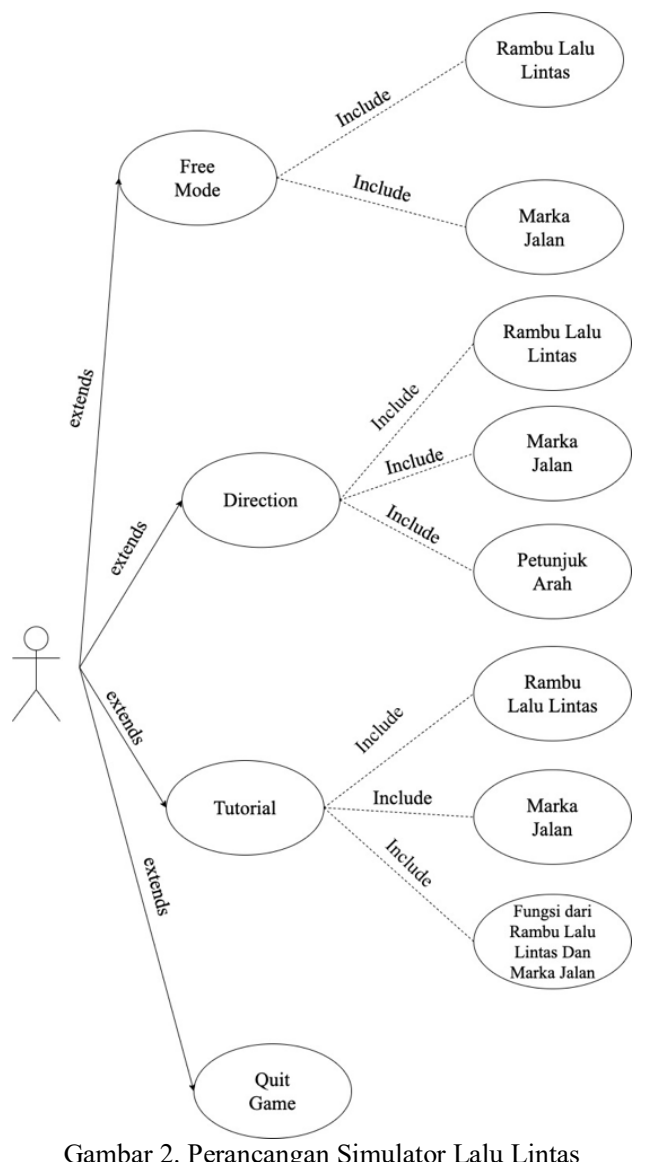

Gambar 2 merupakan perancangan simulator menggunakan metode UML. Metode UML (Unified Modeling Language) merupakan bahasa standar yang digunakan untuk perancangan perangkat lunak. UML berfungsi untuk memvisualisasikan, membuat spesifikasi, membangun dan mendokumentasikan perangkat lunak (SUENDRI, 2018). Penelitian ini menggunakan metode UML agar dapat memvisualisasikan, membuat spesifikasi, membangun dan mendokumentasikan simulator lalu lintas. Terdapat 13 diagram pada UML dan salah satunya adalah use case diagram. Use case diagram adalah pemodelan dari simulator yang akan dibuat. Use case diagram mendeskripsikan interaksi antara user dengan sistem (PUTRA \& ANDRIANI, 2019). Use case diagram dari simulator untuk media pembelajaran lalu lintas di Indonesia. User dapat masuk ke main menu dan dapat memainkan simulator dalam bentuk free mode, direction atau tutorial. Simulator dalam bentuk free mode akan menampilkan rambu lalu lintas dan marka jalan. Simulator dalam bentuk direction akan menampilkan rambu lalu lintas, marka jalan dan petunjuk arah untuk menemukan finish point. Simulator dalam bentuk tutorial akan menampilkan rambu lalu lintas, marka jalan, dan menampilkan penjelasan tentang fungsi dari rambu lalu lintas beserta marka jalan.

\subsection{Implementasi}

Implementasi simulator lalu lintas dilakukan setelah rancangan simulator lalu lintas telah ditentukan. Desain simulator lalu lintas yang telah dirancang diimplementasikan menggunakan tools pembuatan aplikasi 3D yaitu menggunakan Unity 3D. Implementasi desain pada Unity 3D adalah kegiatan pengkodean agar simulator dapat berjalan sesuai dengan desain. Metode yang digunakan pada saat implementasi simulator adalah metode collision detection. Fungsi collision detection untuk memeriksa terjadinya tabrakan antar objek (FASHA, FAUZIAH, \& GUFRONI, 2018).

Simulator lalu lintas menerapkan AI (artificial intelligence) untuk NPC (non-player character). Simulator terlihat lebih nyata apabila memiliki AI pada karakter NPC (KARIM, 2017). NPC pada simulator adalah AI mobil dan AI manusia. Setelah implementasi pada Unity 3D, kemudian simulator di-export menjadi APK (Android application package) untuk dijalankan pada perangkat Android.

\subsection{Pengujian}

Pengujian simulator untuk media pembelajaran lalu lintas di Indonesia dilakukan untuk mengetahui kesesuaian spesifikasi simulator dan dampak dari simulator bagi pemainnya. Metode pengujian yang digunakan adalah usability testing. Tahapan pengujian simulator lalu lintas dapat dilihat pada gambar 3 .

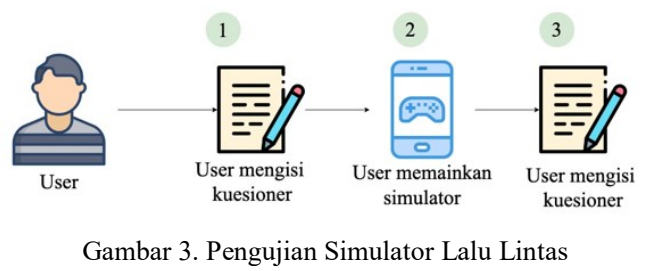

Gambar 3 merupakan pengujian simulator menggunakan metode usability testing. Tahapan pengujian simulator yang pertama adalah user mengisi kuesioner pemahaman user tentang rambu lalu lintas dan marka jalan sebelum bermain simulator, tujuannya adalah untuk mengetahui sejauh mana tingkat pengetahuan user tentang rambu lalu lintas dan marka jalan sebelum 
memainkan simulator. User yang telah mengisi kuesioner kemudian memainkan simulator untuk menguji simulator. User yang sudah memainkan simulator akan mengisi kuesioner lagi untuk memberikan nilai terhadap simulator dan mengisi kuesioner untuk mengukur perkembangan pengetahuan user tentang rambu lalu lintas dan marka jalan setelah bermain simulator, hal ini dilakukan untuk mengukur apakah simulator dapat memberikan edukasi yang baik ke user.

\section{HASIL DAN PEMBAHASAN}

Bagian ini membahas tentang implementasi simulator edukasi lalu lintas. Simulator lalu lintas diimplementasikan pada perangkat Android.

\subsection{Main Menu}

Implementasi halaman main menu simulator edukasi lalu lintas di Indonesia pada perangkat Android dapat dilihat pada gambar 4 .

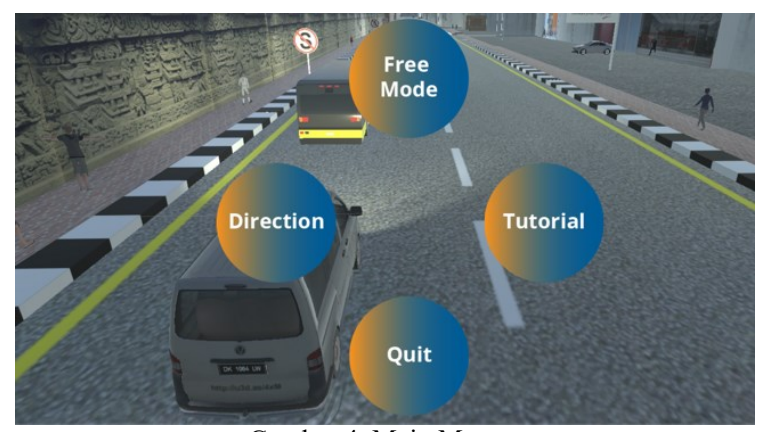

Gambar 4. Main Menu

Gambar 4 merupakan Implementasi halaman main menu pada perangkat Android. Halaman main menu merupakan halaman pertama yang muncul saat user membuka aplikasi. User dapat memilih memainkan free mode scene, direction scene, tutorial scene. Button free mode akan mengarahkan user ke free mode scene, button direction akan mengarahkan user ke direction scene, button tutorial akan mengarahkan user ke tutorial scene, button quit akan mengarahkan user untuk keluar dari aplikasi.

\subsection{Free Mode Scene}

Implementasi scene free mode pada simulator edukasi lalu lintas di Indonesia pada perangkat Android dapat dilihat pada gambar 5.

Gambar 5 merupakan Implementasi free mode scene pada perangkat Android. free mode scene merupakan scene dimana user harus mencapai finish point sebagai tujuan akhir dari scene. Free mode scene merupakan scene utama dari simulator lalu lintas. Tujuan akhir dari free mode scene adalah untuk mencapai finish point tanpa melakukan pelanggaran. Rambu lalu lintas merupakan alat penunjuk jalan yang mengarahkan user untuk mencapai finish point.

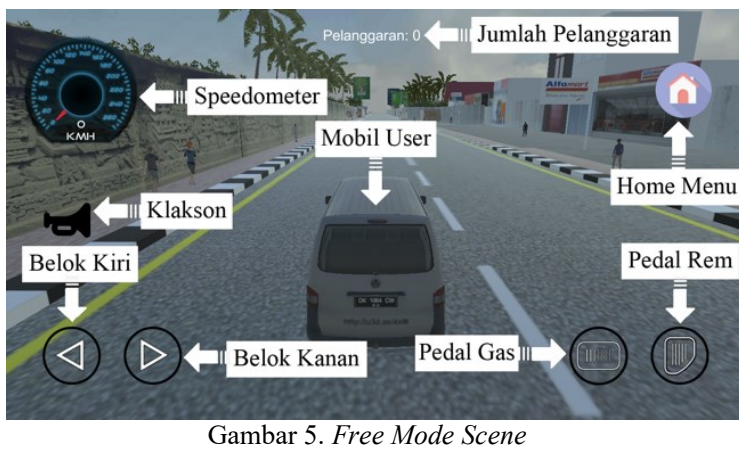

User tidak boleh melanggar rambu lalu lintas dan marka jalan saat memainkan free mode scene, jika user melakukan pelanggaran maka jumlah pelanggaran user akan bertambah dianggap gagal memainkan free mode scene. Jumlah pelanggaran user harus sama dengan nol agar user dinyatakan berhasil memainkan free mode scene.

Simulator lalu lintas menggunakan realistic car controller v3 sebagai library utama pada simulator. Mobil user merupakan bagian realistic car controller v3. Library realistic car controller v3 di-import ke unity kemudian dipilih mobil van sebagai mobil yang akan dikendarai oleh user. Mobil van yang diambil dari library realistic car controller memiliki banyak button, button-button yang tidak diperlukan kemudian dihilangkan. Button-button dari mobil van yang digunakan adalah tombol belok kanan dan belok kiri, pedal gas dan pedal rem, dan elemen speedometer sebagai penunjuk kecepatan.

Klakson pada simulator lalu lintas dibuat menggunakan fungsi button. Button ditambahkan gambar dan suara klakson sehingga dapat menampilkan button yang seolah berbentuk klakson dan mengeluarkan suara klakson saat button ditekan.

Pelanggaran merupakan sebuah text label yang menunjukan jumlah pelanggaran yang dilakukan oleh user. Label pelanggaran dibuat menggunakan text. Jumlah pelanggaran user bertambah oleh trigger jika user melanggar rambu lalu lintas atau marka jalan dan bertambah jika user melakukan collision.

\subsection{Direction Scene}

Direction scene merupakan sebuah scene bantuan yang diberikan kepada user jika user mengalami kendala saat mencari finish point pada free mode scene karena pada free mode scene user hanya mengandalkan rambu lalu lintas saja sebagai pedoman untuk mencapai finish point. Direction scene memberikan petunjuk arah kepada user agar lebih mudah untuk mencapai finish point. Petunjuk arah berupa tanda panah berwarna biru akan muncul di tengah atas layar, saat user berada di pertigaan atau perempatan jalan sehingga user dapat lebih 
mudah menemukan finish point karena diberikan petunjuk arah dengan jelas.

\subsection{Tutorial Scene}

Tutorial scene merupakan sebuah scene yang dibuat agar user dapat mempelajari tentang rambu lalu lintas dan marka jalan yang ada pada simulator saat user memainkan tutorial scene. Tutorial akan muncul ketika user memasuki daerah tertentu. Tutorial yang muncul berupa gambar yang menampilkan sebuah rambu lalu lintas/marka jalan, nama dari rambu lalu lintas/marka jalan, fungsi dari rambu lalu lintas/marka jalan, serta pasal terkait rambu lalu lintas/marka jalan di Indonesia. Tujuan dari scene tutorial adalah untuk memberikan edukasi kepada user mengenai rambu lalu lintas/marka jalan yang ada di Indonesia.

\subsection{Home Menu}

Implementasi home mеnu simulator edukasi lalu lintas di Indonesia pada perangkat Android dapat dilihat pada gambar 6 .

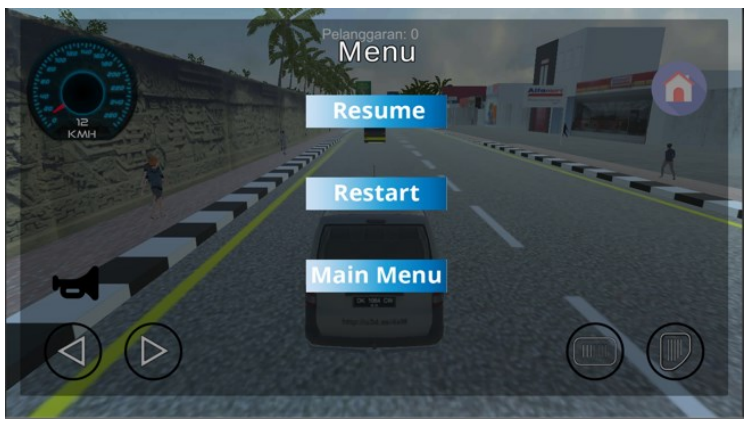

Gambar 6. Home Menu

Gambar 6 merupakan Implementasi home mеnu pada perangkat Android. Home тепи terletak pada bagian kanan atas pada setiap scene di simulator. Home menu dibuat menggunakan button dan ditambahkan gambar rumah yang memiliki arti.

User dapat melakukan jeda pada saat memainkan simulator dengan cara menekan home тепи dan melanjutkan kembali dengan cara memilih resume. User dapat mengulang scene dari awal dengan cara menekan home menu kemudian menekan tombol restart. User dapat kembali ke main menu dengan cara menekan home menu kemudian menekan main menu. Tombol-tombol pada main menu berupa tombol dengan warna biru gradasi putih dan tulisan yang berwarna putih.

\subsection{Finish Point}

Implementasi finish point simulator edukasi lalu lintas di Indonesia pada perangkat Android dapat dilihat pada gambar 7 .

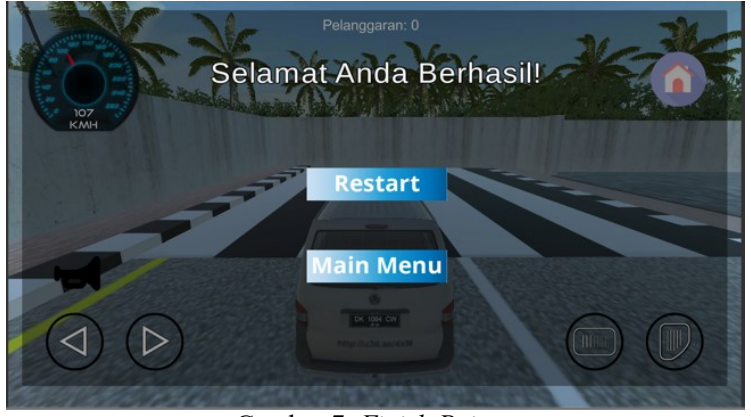

Gambar 7. Finish Point

Gambar 7 merupakan implementasi finish point simulator edukasi lalu lintas pada perangkat Android. Finish point merupakan titik akhir yang harus dicapai oleh user pada setiap scene yang ada di simulator lalu lintas. Finish point menghitung pelanggaran yang dilakukan oleh user selama memainkan scene. User yang tidak pernah melakukan pelanggaran selama memainkan scene pada simulator dianggap berhasil dan bisa kembali ke main menu untuk memainkan scene yang lainnya atau mengulangi scene yang sedang dimainkan. User yang pernah melakukan pelanggaran selama memainkan scene pada simulator dianggap gagal menyelesaikan scene dan harus mengulangi scene tersebut hingga berhasil.

\subsection{Notifikasi Pelanggaran dan Traffic Light}

Implementasi notifikasi pelanggaran dan traffic light simulator edukasi lalu lintas di Indonesia pada perangkat Android dapat dilihat pada gambar 8 .

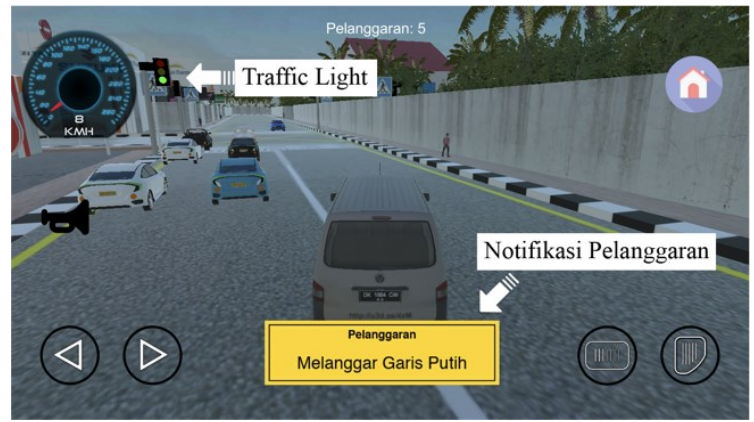

Gambar 8. Notifikasi Pelanggaran dan Traffic Light

Gambar 8 merupakan implementasi notifikasi pelanggaran dan traffic light simulator lalu lintas pada perangkat Android. Notifikasi pelanggaran pada simulator berupa sebuah box kuning yang muncul pada saat user melakukan pelanggaran. Notifikasi pelanggaran muncul ketika user menyentuh trigger pelanggaran atau collision yang dilakukan oleh user. Metode collision detection digunakan untuk memeriksa terjadinya tabrakan antara user dengan objek lainnya. Ketika user menabrak sebuah objek maka collision detection akan mendeteksi telah terjadi sebuah pelanggaran dan memberikan respon dengan menampilkan notifikasi pelanggaran yang telah dilakukan, dan 
menambahkan jumlah pelanggaran user. Notifikasi pelanggaran muncul dan memberitahu pelanggaran apa yang telah dilakukan oleh user sehingga user mengetahui pelanggaran yang telah dilakukan agar user dapat lebih paham terhadap aturan lalu lintas.

Traffic light telah menyala dengan baik sesuai dengan standar yang ada di Indonesia, lampu-lampu yang dimiliki traffic light yaitu lampu merah, lampu kuning, dan lampu hijau. User harus berhenti ketika lampu lalu lintas berwarna merah, user yang tetap jalan ketika lampu traffic light merah dinyatakan melanggar. Jumlah pelanggaran user akan bertambah jika user tetap melaju ketika lampu sedang berwarna merah. User boleh maju ketika lampu traffic light sedang berwarna hijau. User harus berhati-hati atau mengurangi kecepatan kendaraan jika warna lampu traffic light sudah berwarna kuning. Trigger pelanggaran pada traffic light akan aktif pada saat lampu sedang berwarna merah. User yang tetap berjalan maju pada saat lampu sedang merah akan menabrak trigger pelanggaran pada traffic light sehingga jumlah pelanggaran user akan bertambah. Trigger pelanggaran akan non aktif ketika lampu sedang berwarna kuning dan hijau.

\subsection{AI Mobil dan AI Manusia}

AI (artificial intelligence) adalah ilmu komputer yang berkaitan dengan studi dan desain agen cerdas yang memahami lingkungannya dan mengambil tindakan yang memaksimalkan peluang keberhasilannya (POOLA, 2017). Ada dua AI dalam aplikasi ini yaitu AI mobil dan AI manusia, AI mobil dan AI manusia merupakan NPC dan tidak bisa dikendalikan oleh user. AI mobil dan AI manusia dibuat menggunakan Bezier path creator. Bezier path creator memberikan kemudahan bagi pengembang aplikasi di unity 3D. Bezier path creator merupakan kumpulan dari beberapa titik yang digabungkan kemudian membentuk sebuah garis atau disebut dengan path. Setiap karakter manusia/mobil akan diberikan path-nya masing masing. Karakter manusia/mobil akan mengikuti path yang diberikan, karakter mobil/manusia akan start pada titik awal path kemudian mencari titik selanjutnya hingga menemukan titik akhir dari path yang diberikan. Karakter yang sudah menemukan titik akhir dari path-nya akan kembali ke titik awal dan mengulangi tugasnya, hal ini dilakukan secara terus menerus oleh semua karakter mobil/manusia yang digunakan pada simulator.

Tujuan ditambahkan $A I$ mobil/ AI manusia pada simulator untuk menambah kesan real pada saat user bermain simulator. User tidak boleh menabrak $A I$ mobil/manusia yang ada. Jumlah pelanggaran user akan bertambah jika user menabrak $A I$ mobil/manusia.

\subsection{Pengujian Simulator Lalu Lintas}

Metode yang digunakan untuk pengujian simulator lalu lintas adalah usability testing. Usability testing dapat digunakan untuk mengukur sebuah produk telah dapat digunakan oleh user untuk mencapai sebuah goals dengan efektif, efisien dan kepuasan dalam konteks kepuasan tertentu (PUWAKPITIYAGE, RAO, AZIZI, TEE, \& MURUGESAN, 2019). Usability testing digunakan untuk mengukur kepuasan pengguna terhadap simulator dengan menguji sistem ke target pengguna secara langsung. Responden dapat memberikan penilaian terhadap setiap pertanyaan pada kuesioner dengan memilih SS (sangat setuju), S (setuju), C (cukup), TS (tidak setuju), STS (sangat tidak setuju). Setiap pertanyaan dihitung jumlah responden yang memberikan nilai sangat setuju, setuju, cukup, tidak setuju dan sangat tidak setuju kemudian nilai tersebut dijumlahkan dengan pertanyaan lainnya hingga mendapatkan persentase dari jawaban responden.

Tabel 1. Karakteristik Responden Berdasarkan Pekerjaan

\begin{tabular}{ccc}
\hline pekerjaan responden & total & persentase \\
\hline pelajar & 21 & $52,5 \%$ \\
pegawai negeri/ pegawai swasta & 16 & $40 \%$ \\
pengusaha & 3 & $7,5 \%$ \\
polisi/tentara & 0 & $0 \%$ \\
lainnya & 0 & $0 \%$ \\
\hline
\end{tabular}

Tabel 1 merupakan karakteristik dari responden penguji simulator. Responden simulator berjumlah 40 orang. 40 orang responden terdiri dari 21 orang pelajar dengan persentase $52,5 \%, 16$ orang pegawai negeri/pegawai swasta dengan persentase $40 \%$, dan 3 orang pengusaha dengan persentase $7,5 \%$. Karakteristik pekerjaan dari responden mayoritas adalah pelajar dan pegawai negeri/pegawai swasta.

Tabel 2. Karakteristik Responden Berdasarkan Umur

\begin{tabular}{ccc}
\hline umur responden & total & persentase \\
\hline $0-17$ tahun & 0 & $0 \%$ \\
$18-30$ tahun & 40 & $100 \%$ \\
$31-50$ tahun & 0 & $0 \%$ \\
51 tahun keatas & 0 & $0 \%$ \\
\hline
\end{tabular}

Tabel 2 merupakan karakteristik responden penguji simulator berdasarkan umur. Mayoritas umur responden adalah 18 sampai dengan 30 tahun dengan jumlah sebanyak 40 orang dan persentase $100 \%$. Mayoritas responden merupakan penduduk desa yang berumur 17 tahun ke atas dan belum memiliki sim (surat izin mengemudi). Tujuan pengambilan sampel user yang belum memiliki sim untuk memberikan gambaran serta edukasi kepada user tentang rambu lalu lintas dan marka jalan. Edukasi dari simulator tentang rambu lalu lintas dan marka jalan diharapkan dapat digunakan user sebagai dasar pengetahuan untuk mencari sim. 
Tabel 3. Aspek Pemahaman Peraturan Lalu Lintas Sebelum Bermain Simulator

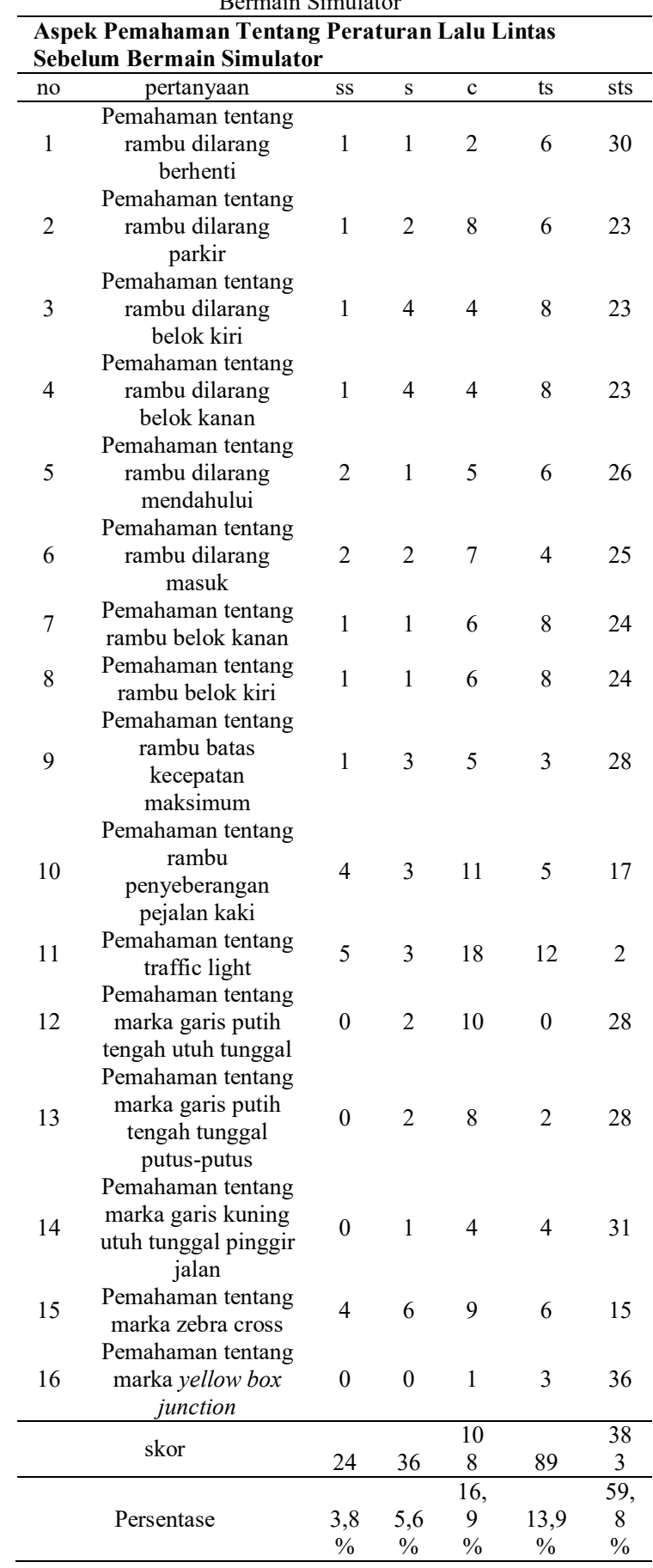

Tabel 3 merupakan kuesioner yang diberikan kepada user sebelum bermain simulator. Kuesioner ini bertujuan untuk mengukur tingkat pengetahuan user tentang peraturan lalu lintas sebelum bermain simulator, peraturan tersebut adalah peraturan rambu lalu lintas dan marka jalan. User diberikan gambar dari rambu lalu lintas dan marka jalan yang ada pada simulator lalu lintas, tujuannya untuk mengukur seberapa paham user dengan fungsi dari rambu lalu lintas dan marka jalan tersebut. User mengisi Pengetahuan user diukur menggunakan kuesioner agar Hasil yang didapat dari 40 orang responden menyatakan masih belum paham terhadap peraturan lalu lintas sebelum bermain simulator. Hasil dari kuesioner ke 40 orang responden menunjukan bahwa pengetahuan responden masih kurang tentang peraturan rambu lalu lintas dan marka jalan. Persentase responden yang belum paham lebih tinggi dari pada persentase yang sudah paham. Persentase responden yang belum paham sebesar $73,8 \%$ (tidak setuju dan sangat tidak setuju) sementara persentase responden yang sudah paham sebesar 9,4\% (sangat setuju dan setuju).

Tabel 4. Aspek Pemahaman Peraturan Lalu Lintas Setelah Bermain Simulator

\begin{tabular}{|c|c|c|c|c|c|c|}
\hline \multicolumn{7}{|c|}{$\begin{array}{l}\text { Aspek Pemahaman Tentang Peraturan Lalu Lintas } \\
\text { Setelah Bermain Simulator }\end{array}$} \\
\hline no & pertanyaan & SS & $\mathrm{s}$ & $\mathrm{c}$ & ts & sts \\
\hline 1 & $\begin{array}{c}\text { Pemahaman tentang } \\
\text { rambu dilarang } \\
\text { berhenti }\end{array}$ & 37 & 3 & 0 & 0 & 0 \\
\hline 2 & $\begin{array}{l}\text { Pemahaman tentang } \\
\text { rambu dilarang } \\
\text { parkir }\end{array}$ & 38 & 2 & 0 & 0 & 0 \\
\hline 3 & $\begin{array}{l}\text { Pemahaman tentang } \\
\text { rambu dilarang } \\
\text { belok kiri }\end{array}$ & 40 & 0 & 0 & 0 & 0 \\
\hline 4 & $\begin{array}{l}\text { Pemahaman tentang } \\
\text { rambu dilarang } \\
\text { belok kanan }\end{array}$ & 40 & 0 & 0 & 0 & 0 \\
\hline 5 & $\begin{array}{l}\text { Pemahaman tentang } \\
\text { rambu dilarang } \\
\text { mendahului }\end{array}$ & 38 & 2 & 0 & 0 & 0 \\
\hline 6 & $\begin{array}{c}\text { Pemahaman tentang } \\
\text { rambu dilarang } \\
\text { masuk }\end{array}$ & 39 & 1 & 0 & 0 & 0 \\
\hline 7 & $\begin{array}{l}\text { Pemahaman tentang } \\
\text { rambu belok kanan }\end{array}$ & 40 & 0 & 0 & 0 & 0 \\
\hline 8 & $\begin{array}{l}\text { Pemahaman tentang } \\
\text { rambu belok kiri }\end{array}$ & 40 & 0 & 0 & 0 & 0 \\
\hline 9 & $\begin{array}{l}\text { Pemahaman tentang } \\
\text { rambu batas } \\
\text { kecepatan } \\
\text { maksimum }\end{array}$ & 38 & 2 & 0 & 0 & 0 \\
\hline 10 & $\begin{array}{c}\text { Pemahaman tentang } \\
\text { rambu } \\
\text { penyeberangan } \\
\text { pejalan kaki }\end{array}$ & 40 & 0 & 0 & 0 & 0 \\
\hline 11 & $\begin{array}{c}\text { Pemahaman tentang } \\
\text { traffic light }\end{array}$ & 40 & 0 & 0 & 0 & 0 \\
\hline 12 & $\begin{array}{l}\text { Pemahaman tentang } \\
\text { marka garis putih } \\
\text { tengah utuh tunggal }\end{array}$ & 39 & 1 & 0 & 0 & 0 \\
\hline 13 & $\begin{array}{l}\text { Pemahaman tentang } \\
\text { marka garis putih } \\
\text { tengah tunggal } \\
\text { putus-putus }\end{array}$ & 40 & 0 & 0 & 0 & 0 \\
\hline 14 & $\begin{array}{c}\text { Pemahaman tentang } \\
\text { marka garis kuning } \\
\text { utuh tunggal pinggir } \\
\text { jalan }\end{array}$ & 40 & 0 & 0 & 0 & 0 \\
\hline 15 & $\begin{array}{l}\text { Pemahaman tentang } \\
\text { marka zebra cross }\end{array}$ & 40 & 0 & 0 & 0 & 0 \\
\hline 16 & $\begin{array}{c}\text { Pemahaman tentang } \\
\text { marka yellow box } \\
\text { junction }\end{array}$ & 38 & 1 & 1 & 0 & 0 \\
\hline & skor & 627 & 12 & 1 & 0 & 0 \\
\hline & Persentase & $\begin{array}{c}97,9 \\
\%\end{array}$ & $\begin{array}{l}1,9 \\
\%\end{array}$ & $\begin{array}{c}0,2 \\
\%\end{array}$ & $\begin{array}{c}0 \\
0\end{array}$ & $\begin{array}{c}0 \\
\%\end{array}$ \\
\hline
\end{tabular}

Tabel 4 merupakan kuesioner yang diberikan kepada user setelah bermain simulator. Kuesioner 
ini bertujuan untuk mengukur tingkat pengetahuan user tentang peraturan lalu lintas setelah bermain simulator. User memainkan simulator beberapa kali sampai user dapat mencapai finish point di free mode scene tanpa melakukan pelanggaran sama sekali. User yang belum dapat menyelesaikan free mode scene tidak diperbolehkan mengisi kuesioner. User memberikan peniliain tentang tingkat pengetahuan yang dimiliki terkait aturan lalu lintas (rambu lalu lintas dan marka jalan) setelah memainkan simulator lalu lintas.

Hasil yang didapat dari 40 orang responden menyatakan bahwa responden telah mengerti tentang peraturan rambu lalu lintas dan marka jalan setelah bermain simulator dengan persentase sebesar 99,8\% (sangat setuju dan setuju).

Tabel 5 merupakan aspek fungsionalitas scene. Hasil pengujian aspek fungsionalitas scene ke 40 orang responden mendapatkan hasil yang bagus (sangat setuju dan setuju). Aspek fungsionalitas scene mendapatkan nilai dengan persentase $91,5 \%$. Aspek fungsionalitas scene diuji oleh responden untuk mengukur segala fungsi-fungsi ada pada simulator lalu lintas.

Tabel 5. Aspek Fungsionalitas Scene

\begin{tabular}{|c|c|c|c|c|c|c|}
\hline \multicolumn{7}{|c|}{ Aspek Fungsionalitas Scene } \\
\hline no & pertanyaan & ss & $\mathrm{s}$ & $\mathrm{c}$ & ts & sts \\
\hline 1 & $\begin{array}{c}\text { Mobil user telah } \\
\text { berfungsi dengan baik }\end{array}$ & 10 & 27 & 3 & 0 & 0 \\
\hline 2 & $\begin{array}{l}\text { Pedal gas telah } \\
\text { berfungsi dengan baik }\end{array}$ & 18 & 16 & 6 & 0 & 0 \\
\hline 3 & $\begin{array}{l}\text { Pedal rem telah } \\
\text { berfungsi dengan baik }\end{array}$ & 14 & 24 & 2 & 0 & 0 \\
\hline 4 & $\begin{array}{l}\text { Tombol belok kiri } \\
\text { telah berfungsi dengan } \\
\text { baik }\end{array}$ & 18 & 16 & 6 & 0 & 0 \\
\hline 5 & $\begin{array}{c}\text { Tombol belok kanan } \\
\text { telah berfungsi dengan } \\
\text { baik }\end{array}$ & 16 & 20 & 4 & 0 & 0 \\
\hline 6 & $\begin{array}{c}\text { Speedometer telah } \\
\text { berfungsi dengan baik }\end{array}$ & 18 & 20 & 2 & 0 & 0 \\
\hline 7 & $\begin{array}{l}\text { Klakson telah } \\
\text { berfungsi dengan baik }\end{array}$ & 14 & 22 & 2 & 2 & 0 \\
\hline 8 & $\begin{array}{l}\text { Perhitungan jumlah } \\
\text { pelanggaran telah } \\
\text { berfungsi dengan baik }\end{array}$ & 14 & 20 & 6 & 0 & 0 \\
\hline 9 & $\begin{array}{l}\text { AI mobil telah } \\
\text { berfungsi dengan baik }\end{array}$ & 8 & 30 & 2 & 0 & 0 \\
\hline 10 & $\begin{array}{c}A I \text { manusia telah } \\
\text { berfungsi dengan baik }\end{array}$ & 8 & 30 & 2 & 0 & 0 \\
\hline 11 & $\begin{array}{l}\text { Traffic light telah } \\
\text { berfungsi dengan baik }\end{array}$ & 7 & 30 & 3 & 0 & 0 \\
\hline 12 & $\begin{array}{l}\text { Efek getar telah } \\
\text { berfungsi dengan baik }\end{array}$ & 10 & 28 & 2 & 0 & 0 \\
\hline 13 & $\begin{array}{c}\text { Notifikasi pelanggaran } \\
\text { telah berfungsi dengan } \\
\text { baik }\end{array}$ & 14 & 24 & 2 & 0 & 0 \\
\hline \multirow{2}{*}{\multicolumn{2}{|c|}{ Skor }} & 16 & 30 & & & \\
\hline & & 9 & 7 & 42 & 2 & 0 \\
\hline \multirow{2}{*}{\multicolumn{2}{|c|}{ persentase }} & 32, & & & & \\
\hline & & $\begin{array}{c}5 \\
\%\end{array}$ & $\begin{array}{l}59 \\
\%\end{array}$ & $\begin{array}{c}8,1 \\
\%\end{array}$ & $\begin{array}{c}0,4 \\
\%\end{array}$ & $\begin{array}{c}0 \\
\%\end{array}$ \\
\hline
\end{tabular}

Fungsi yang tidak berjalan dengan baik akan mendapat nilai rendah dari responden sedangkan fungsi yang telah berjalan dengan baik akan mendapat nilai tinggi oleh responden.
Tabel 6. Aspek Fungsionalitas Menu

\begin{tabular}{|c|c|c|c|c|c|c|}
\hline \multicolumn{7}{|c|}{ Aspek Fungsionalitas Menu } \\
\hline no & pertanyaan & ss & $\mathrm{s}$ & $\mathrm{c}$ & ts & sts \\
\hline 1 & $\begin{array}{l}\text { tombol home menu } \\
\text { telah berfungsi dengan } \\
\text { baik }\end{array}$ & 13 & 24 & 3 & 0 & 0 \\
\hline 2 & $\begin{array}{l}\text { tombol resume telah } \\
\text { berfungsi dengan baik }\end{array}$ & 12 & 24 & 4 & 0 & 0 \\
\hline 3 & $\begin{array}{l}\text { tombol restart telah } \\
\text { berfungsi dengan baik } \\
\text { tombol main menu }\end{array}$ & 12 & 26 & 2 & 0 & 0 \\
\hline 4 & $\begin{array}{l}\text { telah berfungsi dengan } \\
\text { baik }\end{array}$ & 14 & 22 & 4 & 0 & 0 \\
\hline & skor & 51 & 96 & 13 & 0 & 0 \\
\hline & persentase & $\begin{array}{c}31, \\
9 \\
\%\end{array}$ & $\begin{array}{l}60 \\
\%\end{array}$ & $\begin{array}{c}8,1 \\
\%\end{array}$ & $\begin{array}{c}0 \\
\%\end{array}$ & $\begin{array}{c}0 \\
\%\end{array}$ \\
\hline
\end{tabular}

Tabel 6 merupakan aspek fungsionalitas menu. Hasil pengujian aspek fungsionalitas menu ke 40 orang responden mendapatkan hasil yang bagus (sangat setuju dan setuju). Aspek fungsionalitas menu mendapatkan nilai dengan persentase $91,9 \%$.

\begin{tabular}{|c|c|c|c|c|c|c|}
\hline \multicolumn{7}{|c|}{ Aspek Grafis } \\
\hline no & pertanyaan & SS & $\mathrm{s}$ & $\mathrm{c}$ & ts & sts \\
\hline 1 & $\begin{array}{l}\text { Lingkungan pada } \\
\text { simulator memiliki } \\
\text { desain yang baik }\end{array}$ & 20 & 14 & 6 & 0 & 0 \\
\hline 2 & $\begin{array}{l}\text { Mobil user memiliki } \\
\text { desain yang baik }\end{array}$ & 8 & 24 & 8 & 0 & 0 \\
\hline 3 & $\begin{array}{l}\text { AI mobil memiliki } \\
\text { desain yang baik }\end{array}$ & 6 & 28 & 6 & 0 & 0 \\
\hline 4 & $\begin{array}{c}\text { AI manusia memiliki } \\
\text { desain yang baik } \\
\text { Rambu-rambu lalu }\end{array}$ & 8 & 26 & 6 & 0 & 0 \\
\hline 5 & $\begin{array}{c}\text { lintas memiliki desain } \\
\text { yang baik }\end{array}$ & 16 & 24 & 0 & 0 & 0 \\
\hline 6 & $\begin{array}{c}\text { Marka-marka jalan } \\
\text { memiliki desain yang } \\
\text { baik }\end{array}$ & 16 & 24 & 0 & 0 & 0 \\
\hline 7 & $\begin{array}{l}\text { Menu-Menu pada } \\
\text { simulator memiliki } \\
\text { desain yang baik }\end{array}$ & 9 & 23 & 8 & 0 & 0 \\
\hline \multirow{2}{*}{\multicolumn{2}{|c|}{ skor }} & & 16 & & & \\
\hline & & 83 & 3 & 34 & 0 & 0 \\
\hline \multirow{2}{*}{\multicolumn{2}{|c|}{ persentase }} & $\begin{array}{c}29, \\
6\end{array}$ & $\begin{array}{c}58, \\
2\end{array}$ & $\begin{array}{c}12, \\
1\end{array}$ & 0 & 0 \\
\hline & & $\%$ & $\%$ & $\%$ & $\%$ & $\%$ \\
\hline
\end{tabular}

Tabel 7 merupakan aspek grafis. Hasil pengujian aspek grafis ke 40 orang responden mendapatkan hasil yang bagus (sangat setuju dan setuju). Aspek grafis mendapatkan nilai dengan persentase $87,8 \%$.

Tabel 8. Aspek Ergonomis

\begin{tabular}{lcccccc}
\hline Aspek Ergonomis & & & & & \\
\hline no & pertanyaan & ss & s & c & ts & sts \\
\hline \multicolumn{1}{c}{$\begin{array}{c}\text { Simulator lalu lintas } \\
\text { memiliki menu-menu } \\
\text { yang mudah untuk } \\
\text { melakukan navigasi } \\
\text { objek }\end{array}$} & 5 & 31 & 4 & 0 & 0 \\
2 & $\begin{array}{c}\text { Menu-menu navigasi } \\
\text { nyaman dioperasikan } \\
\text { Suara yang muncul } \\
\text { pada aplikasi terdengar } \\
\text { jelas }\end{array}$ & 5 & 30 & 5 & 0 & 0 \\
\hline skor & 19 & 89 & 12 & 0 & 0 \\
\hline
\end{tabular}




\begin{tabular}{rccccc}
\hline Aspek Ergonomis & \multicolumn{1}{c}{} & & & \\
\hline & 15, & 74, & & & \\
persentase & 8 & 2 & 10 & 0 & 0 \\
& $\%$ & $\%$ & $\%$ & $\%$ & $\%$ \\
\hline
\end{tabular}

Tabel 8 merupakan aspek ergonomis. Hasil pengujian aspek ergonomis ke 40 orang responden mendapatkan hasil yang bagus (sangat setuju dan setuju). Aspek ergonomis mendapatkan nilai dengan persentase $90 \%$.

Tabel 9 merupakan aspek user experience. Hasil pengujian aspek user experience ke 40 orang responden mendapatkan hasil yang bagus (sangat setuju dan setuju). Aspek user experience mendapatkan nilai dengan persentase $95,8 \%$.

Tabel 9. Aspek User Experience

\begin{tabular}{|c|c|c|c|c|c|c|}
\hline \multicolumn{7}{|c|}{ Aspek User Experience } \\
\hline no & pertanyaan & Ss & $\mathrm{S}$ & $\mathrm{c}$ & ts & sts \\
\hline 1 & $\begin{array}{l}\text { Simulator memiliki } \\
\text { tujuan yang jelas }\end{array}$ & 18 & 21 & 1 & 0 & 0 \\
\hline 2 & $\begin{array}{l}\text { Finish point pada } \\
\text { simulator lalu lintas } \\
\text { mudah untuk } \\
\text { ditemukan }\end{array}$ & 9 & 24 & 7 & 0 & 0 \\
\hline & $\begin{array}{c}\text { Simulator lalu lintas } \\
\text { memberikan }\end{array}$ & & & & & \\
\hline 3 & $\begin{array}{l}\text { pengalaman yang } \\
\text { menyenangkan saat } \\
\text { dimainkan }\end{array}$ & 14 & 24 & 2 & 0 & 0 \\
\hline 4 & $\begin{array}{l}\text { Edukasi tentang rambu } \\
\text { lalu lintas pada } \\
\text { simulator dapat } \\
\text { diterima dengan baik }\end{array}$ & 38 & 2 & 0 & 0 & 0 \\
\hline 5 & $\begin{array}{c}\text { Edukasi tentang marka } \\
\text { jalan pada simulator } \\
\text { dapat diterima dengan } \\
\text { baik }\end{array}$ & 38 & 2 & 0 & 0 & 0 \\
\hline 6 & $\begin{array}{l}\text { Simulator lalu lintas } \\
\text { telah memenuhi } \\
\text { ekspektasi sebagai } \\
\text { media pembelajaran } \\
\text { lalu lintas di Indonesia }\end{array}$ & 20 & 20 & 0 & 0 & 0 \\
\hline \multirow{2}{*}{\multicolumn{2}{|c|}{ skor }} & 13 & & & & \\
\hline & & 7 & 93 & 10 & 0 & 0 \\
\hline \multirow{3}{*}{\multicolumn{2}{|c|}{ persentase }} & & 38 , & & & \\
\hline & & 57 & 8 & 4,2 & 0 & 0 \\
\hline & & $\%$ & $\%$ & $\%$ & $\%$ & $\%$ \\
\hline
\end{tabular}

\section{KESIMPULAN}

Simulator lalu lintas merupakan media yang dapat memberikan edukasi kepada masyarakat tentang aturan lalu lintas secara efektif dan efisien. Simulator lalu lintas dapat digunakan oleh semua golongan masyarakat karena simulator berjalan pada perangkat Android.

Simulator lalu lintas diuji menggunakan metode usability testing terhadap user menunjukan hasil yang baik. Simulator edukasi lalu lintas dapat meningkatkan pengetahuan user tentang rambu lalu lintas dan marka jalan. Masyarakat yang akan mencari SIM (Surat Ijin Mengemudi) dapat melakukan latihan terlebih dahulu pada simulator lalu lintas sebelum mengikuti ujian SIM, agar masyarakat mempunyai gambaran mengenai aturan lalu lintas yang ada.

\section{DAFTAR PUSTAKA}

FASHA, L., FAUZIAH, F., \& GUFRONI, M., 2018. Implementasi Algoritma Collision Detection pada Game Simulator Driving Car. Jurnal String, pp.58-65.

JAYA, I., BUANA, P., \& WIRANATHA, A., 2015. Game Edukasi Rambu Lalu Lintas Berbasi Android. Merpati, pp.190-201.

KARIM, S., 2017. Perubahan perilaku Non-Player Character (NPC) pada Game Arabic Hunter menggunakan Jaringan Syaraf Tiruan Perceptron. Jurnal Ilmiah Teknologi Sistem Informasi, pp.34-41.

KUSNIYATI, H., \& SITANGGANG, N., 2016. Aplikasi Edukasi Budaya Toba Samosir Berbasis Android. JURNAL TEKNIK INFORMATIKA, pp.9-18.

POOLA, I., 2017. How Artificial Intelligence in Impacting Real Life Every day. International Journal of Advance Research and Development, 2(10), pp.96-100.

PRAYOGA, P., BUANA, P., \& WIRANATHA, A., 2017. Rancang Bangun Aplikasi Permodelan Sambungan Kayu (Wood Joint) dengan Objek 3D Berbasis Android. Merpati, 5, pp.162-172.

PRAYUDA, I., BAYUPATI, I., \& WIRANATHA, A., 2016. Rancang Bangun Game The Adventure of Timun Emas Berbasis Android. Merpati, 4, pp.214-224.

PUTRA, D., \& ANDRIANI, R., 2019. Unified Modelling Language (UML) dalam Perancangan Sistem Informasi Permohonan Pembayaran Restitusi SPPD. Jurnal TEKNOIF, pp.32-39.

PUWAKPITIYAGE, C., RAO, V., AZIZI, M., TEE, W., \& MURUGESAN, R., 2019. A Proposed Web Based Real Time Brain Computer Interface (BCI) System for Usability Testing. International Journal of Online and Biomedical Engineering, 15, pp.111-123.

RAJAGUKGUK, A., \& PURBA, D., 2018. Game Edukasi Rambu Lalu Lintas Berbasis Android dengan Metode Fisher-Yates. Jurnal Teknik Informatika Unika St. Thomas (JTIUST), 3, pp.133-143.

SUENDRI, S., 2018. Implementasi Diagram UML (Unified Modelling Language) Pada Perancangan Sistem Informasi Remunerasi Dosen Dengan Database Oracle (Studi Kasus: UIN Sumatera Utara Medan). Jurnal Ilmu Komputer dan Informatika, pp.1-9.

SYUKWANSYAH, D., 2016. Pengembangan Bisnis Joeragan dengan Menggunakan Pendekatan Prinsip Efektual. PERFORMA $\therefore$ Jurnal Manajemen dan Start-Up Bisnis, pp.152-161. 
274 Jurnal Teknologi Informasi dan Ilmu Komputer (JTIIK), Vol. 8, No. 2, April 2021, hlm. 265-274

TRISTIANTO, C., 2018. Penggunaan Metode Waterfall untuk Pengembangan Sistem Monitoring dan Evaluasi Pembangunan Pedesaan. ESIT : Jurnal Teknologi Informasi, pp.8-22.

UTAMA, G., \& MARIADI, N., 2019. Penerapan Hukum Terhadap Pelanggar RambuRambu Lalu Lintas Yang Di Buat Oleh Dinas Perhubungan (Studi Di Polres Buleleng). Kertha Widya Jurnal Hukum, 7, pp.71-89.

VLACHOPOULOS, D., \& MAKRI, A., 2017. The Effect of Games and Simulations on Higher Education: A Systematic Literature Review. International Journal of Educational Technology in Higher Education, pp.1-33. 